\title{
LA SOCIALIZACIÓN A TRAVÉS DE LAS REDES
}

\author{
Beatriz Peña Acuña \\ Universidad Católica San Antonio \\ bpena@pdi.ucam.edu
}

Ensayo original autorizado para su primera publicación en la revista académica REDMARKA. Revista Digital de Marketing Aplicado

https://doi.org/10.17979/redma.2011.02.07.4732

Recibido: 23 Septiembre 2011

Aceptado: 20 Noviembre 2011

\section{Resumen}

Esta disertación pretende afrontar ciertos aspectos socioculturales desconocidos que programa la presencia de las redes sociales y que se muestran de interés en el ámbito social en general. Primero, nos interesa trazar cómo el concepto de "red" (net) se idea y contextualiza dentro del portento tecnológico como es "Internet", así como se describen los principales tipos de redes sociales más populares. Segundo, para otorgar una base filosófica se abordan dos perspectivas acerca de la naturaleza de lo que en sí son las redes sociales en cuanto a la relación real-virtual que se establece entre los interesados. Tercero, se investiga acerca de los nuevos efectos psicosociales del uso de ciberespacio a través de opiniones y estudios realizados, en general, y las redes sociales en concreto. Cuarto, se reflexiona sobre cómo la usanza de redes sociales puede popularizar el acrecentamiento de los eventos sociales y acontecimientos culturales, en definitiva, cómo edifica nuevos espacios de expansión en diversos ámbitos sociales.

Para fundamentar el texto se ha buscado un soporte filosófico que aporte una base para la indagación psicológica y social-cultural posterior. Asimismo se ha realizado una descripción sobre el fenómeno de las redes sociales y una revisión de la literatura acerca de los efectos que pueda tener en la sociedad. Además se contaba con un estudio previo colateral sobre el fenómeno de redes 
sociales referido a movimientos políticos. Con este estudio se busca teorizar y sugerir posibles caminos de influencia que pueden tomar las redes. Como resultados apuntamos que las redes facilitan una plataforma de interacción y organización social que reproduce y a la vez se adapta a la propia naturaleza social humana. Además avistamos que se puede dar de forma idónea el aprendizaje social y cierta construcción social global en un mundo de cambios rápidos conductuales y éticos.

Sin embargo, existen autores escépticos: no le otorgan tanta importancia a las redes o a sus efectos, a pesar de los hechos políticos probados del 11-M en España o las rebeliones sociales recientes de algunos países árabes bajo tiranías. Otros autores insisten en la brecha digital que existe entre los países desarrollados y subdesarrollados.

Palabras clave: Red, Internet, sociedad, redes sociales

\section{Abstract}

This paper seeks to address socio-cultural aspects unknown to program the presence of social networks and shown interest in the social policy field in general. First, we want to trace how the concept of "net" (net) it is being designed and contextualized within the framework of the emergence of technological wonder as Internet. Second, we provide a philosophical basis examines two perspectives on the nature of what they themselves are social networks in terms of real-virtual relationship that exists between stakeholders. Third, we expose new researches about the psychosocial effects of the use of cyberspace through opinions and studies, in general, and social networks in particular. Fourth, we examine how the usage of social networks can popularize the enhancement of social events and cultural events, ultimately, how it builds new areas of expansion in different social environments.

In support of the text has sought a philosophical underpinning to provide a basis for inquiry and social-cultural psychological later. It has also made a description of the social networking phenomenon and a review of the literature on the effects it can have on society. In addition, a previous study had collateral on the social networking phenomenon refers to political movements. This study seeks 
to theorize and suggest possible avenues of influence that can make the networks. As a result we noted that networks facilitate a platform for interaction and social organization that plays while adapting to the social nature of man. Also it is sighted that nets can give a suitable social learning and social construction in a global world of rapid change and ethical behavior.

However, some authors do not give much importance to networks or its effects, despite the political events of the 11-M tested in Spain and the recent social transgressions of some Arab countries under tyranny. Moreover some authors insist on the digital divide between developed and underdeveloped countries.

Keywords: Network, Internet, society, social networks 


\begin{abstract}
"Facebook nació para dar a la gente el poder de compartir y hacer del mundo un lugar más abierto y conectado" Mark Zuckerberg, creador de Facebook
\end{abstract}

Introducción

Las nuevas generaciones han recibido una educación informática y multimedia prevista por las organizaciones europeas e internacionales que ve hoy en día sus frutos con una mentalidad nueva de las posibilidades que el espacio virtual les puede ofrecer. Esa educación se ve actualmente reflejada en una nueva manera de operar cívicamente.

Interesa por ello, indagar y profundizar en este fenómeno tecnológico nuevo así como profundizar en la naturaleza psicológica y social humana de modo que se puedan prever ciertos efectos y un cambio de la mentalidad social por las posibilidades que esta herramienta brinda al individuo y a su cohesión social.

1.-El concepto de red contextualizado en el fenómeno Internet

Como hemos anunciado el concepto de "red" (net en inglés) se entiende y contextualiza dentro del marco de aparición del fenómeno tecnológico como es Internet.

Este fenómeno surge de la interacción entre la ciencia, la investigación universitaria, los programas de investigación militar y resulta favorecido por la mentalidad libertaria y filantrópica de sus creadores.

La idea primitiva para su concepción fue militar: se concebía crear una red de nódulos de información que si era destruida no facilitara la información de otros nódulos que seguirían conectados y realizando su trabajo. Como hemos opinado anteriormente en otra disertación:

Me ha gustado que Tim Berners- Lee haya explicado, en el artículo "Tejiendo la Red" en el año 2000, hace ya una década, que la génesis de la Web ha tenido REDMARKA UIMA-Universidad de A Coruña - CIECID 
en cuenta el parámetro psicosocial, la interconexión humana y la comunicación universal a través de vivencias personales. Valoro que este creador haya diseñado la Red desde una filosofía tolerante, universalista y democrática, aunque no lo explicita, en la que busca que se puedan crear superestructuras transnacionales y que se puedan dar iniciativas alternativas a las que gestionan los naciones o las agrupaciones grandes de naciones como la ONU, o la OTAN, para buscar solución a los problemas comunes o para dirigir la evolución de la historia del mundo. Pero todavía veo que esta posibilidad está en un estadio muy idealista1.

De esta manera se entiende red como una trama de nódulos autónomos y relacionados, tal y como es la propia naturaleza humana y su vertiente relacional: individual y social, y tal y como se conforman las unidades o grupos sociales, como expondremos a continuación.

El ciberespacio ha sido acogido por los países desarrollados que han invertido en investigación en nuevas tecnologías y en proyectos educativos desde hace décadas. Manuel Castells explica la importancia de este nuevo recurso tecnológico que forma parte de nuestro contexto cultural:

Internet es el tejido de nuestras vidas en este momento [...]. Se trata de una red de redes de ordenadores capaces de comunicarse entre ellos. [...] Sin embargo, esa tecnología es mucho más que una tecnología. Es un medio de comunicación, de interacción y de organización social [...]. Internet es ya y será aún más el medio de comunicación y de relación esencial sobre el que se basa una nueva forma de sociedad que ya vivimos, que es lo que yo llamo la sociedad red.2

\footnotetext{
${ }^{1}$ PEÑA ACUÑA, B. Entender el origen y la naturaleza de Internet, Revista Vivat Academia, marzo 2010, p.1. Extraído el 11 de diciembre de 2011, de http://www.ucm.es/info/vivataca/numeros/n110/ensayos.htm\#entender

${ }^{2}$ Castells, M., "INTERNET Y LA SOCIEDAD RED", Conferencia de presentación del Programa de Doctorado sobre la Sociedad de la información y el Conocimiento, Universitat Oberta de Catalunya, 7-10-2000, p.1. Extraído el 11 de diciembre de 2011, de http://tecnologiaedu.us.es/bibliovir/pdf/106.pdf . 
Javier Celaya realiza una clasificación tipológica de las redes sociales que nos introduce a la cuestión a tratar. Este experto en comunicación establece tres tipos de redes sociales con una descripción3:

Las redes profesionales (Linkedin, Xing, Viadeo, etc.). En estas plataformas, la mayoría de los miembros las utilizan para incrementar y gestionar su red de contactos con fines profesionales. Independientemente del sector a que pertenezca, cualquier usuario puede establecer nuevos contactos profesionales con usuarios de diferentes actividades académicas o profesionales, contratar asesoramiento de especialistas, buscar trabajo, participar en eventos, conocer otros puntos de vista profesionales, etc.Xing, Linkedin y Viadeo son las redes sociales de contactos profesionales con mayor número de usuarios en España. Estas redes fomentan el empleo a través de la interacción entre profesionales y empresas interesadas en detectar talento.

Las redes generalistas (MySpace, Facebook, Tuenti, Hi5, etc.) cuentan con un gran número de usuarios con perfiles totalmente dispares y comportamientos diferentes. No obstante, para que sus miembros tengan la sensación de pertenecer a una comunidad, estas plataformas generalistas permiten a los usuarios crear subgrupos de intereses comunes para atender necesidades específicas de un colectivo concreto.

Las redes especializadas (Ediciona, eBuga, CinemaVIP, 11870, etc.). Son plataformasdedicadas a una determinada actividad social o económica, por ejemplo, Flixster, una red de amantes del cine, SkiSpace especializada en el deporte de la nieve, etc. Entre ellas las redes de contactos personales son las que tienen más tráfico en nuestro país como Meetic, Match.com, Badoo y Gaydar.

\footnotetext{
${ }^{3}$ Celaya, J., 2008, LA EMPRESA EN LA WEB 2.0, Gestión 2000, 3ª edición, pp.96-97 REDMARKA UIMA-Universidad de A Coruña - CIECID Año IV, Número 7, (2011), v2 pp. 3-24 http://www.redmarka.org/ 
2.-Ontología de las redes respecto a la sociabilidad virtual y real de los usuarios.

Es sabido que Sócrates, Platón y Aristóteles sentaron las bases del discurso antropológico en Occidente al considerar al ser humano con un estatuto ontológicamente específico. A partir de Sócrates es reconocido que la filosofía griega abandonó básicamente la Naturaleza a fin de ocuparse del ser humano. Si tenemos que barajar una fundamentación antropológica filosófica que nos apoye en nuestra reflexión nos decantamos por la formulación clásica aristotélica como punto de partida. Aristóteles concibe que la naturaleza de la persona se componga por un carácter individual y un aspecto social. Ambos conforman al hombre, tanta fuerza contiene el primer factor como el segundo.

En segundo lugar consideramos conveniente considerar el proceso de comunicación entre los individuos bajo un prisma psicosocial, en concreto, la teoría interpretativa del "interaccionismo simbólico", pues nos parece que es la que más se adecua a la perspectiva del proceso de transmisión de valores -de los que hablaremos en un epígrafe más adelante-, formulación que surgió en los años 30, de manera especial según la concepción de George H. Mead y Herbert Blumer.

La elección de la teoría de la interacción de Blumer se debe a que en ella se concibe al emisor y al receptor como individuos activos y libres que por la interacción social con los otros participantes conforman los significados que interpretan la realidad social. Otra ventaja que presenta la teoría de la interacción microsociológica es que se tiene en cuenta el grado de instrucción o background del actor (o agente). $Y$ en tercer lugar, da importancia al contexto cultural que afecta al agente en el que incluimos la tendencia progresiva al uso de las nuevas tecnologías incluso por la administración pública.

Asimismo tenemos en cuenta a Erving Goffman, el cual aparece en el panorama intelectual en los años 70 , con su interesante análisis dramático sobre el aprendizaje social, formulación que se desarrolla en consonancia con la teoría de la interacción. Su aportación sugiere que el aprendizaje social lo 
facilita la misma situación dramatúrgica que reproduce el cine4. Goffman se ha inspirado, a su vez, en Edmund Burke y su planteamiento dramatúrgico del comportamiento social5, mientras que Burke lo ha hecho partiendo de la antigüedad clásica, pues creía que el sentido de la tragedia griega cumplía un aprendizaje cultural, social y comunitario para saber comportarse según el ideal del ciudadano de la civis. Goffman ha descubierto hasta qué punto el comportamiento es debido a otros y regulado por los roles sociales y lo que esos otros esperan de nosotros, porque si algo tiene una aceptación común, confían en que cada uno lo acepte, en principio, también6.

Además esta teoría interpretativa es afín con la postura antropológica aristotélica que, si cabe, interpenetra la base teórica que establecemos para especular en este artículo sobre las redes sociales, con el fin de darle más solidez y unidad. Esta concepción afirma que el hombre posee una libertad individual y un fuerte carácter social7, por ejemplo, cuando afecta a las relaciones entre amigos o internautas, como veremos.

La afinidad entre la postura aristotélica e interpretativa se descubre porque en esta segunda teoría es defendible la libertad individual como base y fuente primera de elección e interpretación, con influencia de la interacción social, sobre todo respecto de las personas con las que guarda un vínculo más fuerte o las que tienen instrucción educativa. En segundo lugar, esta teoría valora la influencia del receptor en el contexto social.

Erving Goffman explica la articulación de dos factores: la asimilación individual y la asimilación social desde la interacción en su libro La presentación de la vida cotidiana:

El individuo se presenta y presenta su actividad ante otros, en las situaciones de trabajo corriente, en qué forma guía y controla la impresión que los otros se

\footnotetext{
${ }^{4}$ Goffman, E., 1997, LA PRESENTACIÓN DE LA PERSONA EN LA VIDA COTIDIANA, Amorrutu editores,Buenos Aires,, p. 27.

${ }^{5}$ Martín Algarra, M., 2003, TEORÍA DE LA COMUNICACIÓN: UNA PROPUESTA, Madrid: Tecnos, pp. 109-111.

${ }^{6}$ Rodrigo Alsina, M., 2001, TEORÍAS DE LA COMUNICACIÓN: ÁMBITOS, MÉTODOS Y PERSPECTIVAS, Barcelona: Servei de Publicacions de la Universitat Autonoma de Barcelona, Bellaterra,, pp. 171-174.

${ }^{7}$ Aristóteles, 2004, Ética a Nicómaco, Madrid: Losada. REDMARKA UIMA-Universidad de A Coruña - CIECID Año IV, Número 7, (2011), v2 pp. 3-24 http://www.redmarka.org/ 
forma de él y qué tipo de cosas puede y no puede hacer mientras actúa ante ellos8.

Según el ambiente en el que se encuentre, vendrán exigidas las líneas de actuación que deberá seguir; su comportamiento dependerá del encuadre que realice de la situación. Se pone un ejemplo que ilustra la definición de situación: una misma persona es padre en su hogar, director de un colegio en su trabajo y un alumno de inglés. El rol que cumple en las tres situaciones es distinto y su comportamiento tiene que corresponder a cada una de las tres situaciones. En la primera desarrolla la paternidad con lo que supone de autoridad y comprensión con sus hijos; en la segunda, dirige y tiene autoridad sobre padres, profesores y alumnos, y en la tercera como alumno aprende y se deja dirigir por otra autoridad.

Erving Goffman además comparte la afirmación de Giuseppe Tanzella Niti9 de que la mejor comunicación es siempre la de persona a persona cara a cara. Expone en este libro -La presentación de la vida cotidiana- que la influencia en la interacción interpersonal es más fuerte que en otra mediatizada, porque se da una confrontación cara a cara en la experiencia personalizada.

Podríamos acudir a otros tres fenómenos para defender la comunicación física, real entre personas: la necesidad de percibir por los sentidos al otro-como otro modo primario y natural de conocimiento-,la experiencia emocional compartida y la empatía que facilita el apoyo emocional, necesario entre las personas con el fin de crear o afianzar vínculos afectivo-emocionales. Según la definición del Diccionario de la Academia, la empatía es "la identificación mental y afectiva de un sujeto con el estado de ánimo de otro."10 El psicólogo Rogers definió la empatía como la percepción exacta de la emoción del otro como si uno fuera esa persona, pero sin perder la condición de observador. Sin embargo, otros

\footnotetext{
${ }^{8}$ Goffman, E., LA PRESENTACIÓN DE LA PERSONA EN LA VIDA COTIDIANA, p. 11 en Rodrigo Alsina, M. 2001, Op.cit., p. 172.

${ }^{9}$ Tanzella Nitti, G., 20-9-1997, "LA DIMENSIÓN TEOLÓGICA DE LA COMUNICACIÓN", Roma, Centro Internazionale di Studi, conferencia inédita.

${ }^{10} \mathrm{VV}$. AA. DICCIONARIO DE LA REAL ACADEMIA DE LA LENGUA ESPAÑOLA. Recuperado el 12 de diciembre de 2011, de http://buscon.rae.es/drael/SrvltConsulta?TIPO BUS=3\&LEMA=empatía 
psicólogos que le siguieron empezaron a confundir ese estado de empatía con la manifestación11.

Por la tanto, sintetizando lo expuesto anteriormente sobre la interacción, el actor se ve influido de forma individual por el valor que se transmite a través de las redes, pero el proceso de asimilación de ese valor es más complejo, cuestión que no trataremos en este artículo. Además, está expuesto a una dinámica de elección y toma de posición frente a los valores, modelos, estereotipos, estilos de vida, modas, etc., por la misma interacción en su contexto social habitual, que le reclama una respuesta. Igualmente, se requiere un aprendizaje constante de las expectativas de los otros participantes respecto al papel y al rol que esperan que represente.

De lo anteriormente dicho, deducimos varias formulaciones importantes. Primera, la comunicación entre dos individuos como deseable, auténtica y real se da entre estos en una situación real frente a frente, con cercanía física con posibilidad de percepción no sólo del lenguaje emitido, sino también de la posible lectura del lenguaje corporal.

Segunda, el vínculo afectivo emocional real con una persona permite la situación virtual, es una prolongación de ese conocimiento previo mutuo que puede favorecer el contacto.

Tercero, la relación virtual puede favorecer una relación real, pero si se mantiene per se, no deja de ser ontológicamente una relación seudo-real. Descubrimos que el hecho de que una persona tenga muchos contactos en la red no le asegura estar vacunado contra la soledad emocional, si le falta una conexión real con sus contactos y sólo establece una relación superficial. Además la comunicación a través de una pantalla guarda cierto anonimato, y puede enmascarar reacciones y emociones falsas que en una relación cara a cara se desvelarían por el lenguaje corporal.

Cuarto, el hecho de que un individuo sólo promueva relaciones sociales en redes y no fomente las reales, es un síntoma de negación, de que no acepta las ventajas e inconvenientes de las relaciones sociales. Pueden darse varios

\footnotetext{
${ }^{11}$ Ortony, A. y otros, 1996, LA ESTRUCTURA COGNITIVA DE LAS EMOCIONES, Madrid: Siglo XXI, Madrid, p. 330. 
casos si sólo utiliza la redes sociales para socializarse, por ejemplo, el internauta evita los riesgos de una socialización normal de forma temporal debido a un trauma (pérdida, separación o divorcio traumático reciente), o de alguna forma muestra algún hándicap o inadaptación social por tener un carácter difícil -presentar un perfil egocéntrico, histriónico, obsesivocompulsivo, inestable, etc., o por tener complejo debido a un defecto físico o mental-, o alguna anomalía a la hora de afrontar una sociabilidad normal (fobia, estilo antisocial-pendenciero, estilo esquizoide-ermitaño, etc.).

Esta evasión como huida de la realidad social-que reconocemos que es tarea compleja- a través de las redes es la que sostenemos que no es conveniente, ni saludable para la persona. En efecto, lo deseable es que los lazos establecidos por Internet se complementen con el contacto real.

El estudio de la Asociación de Investigación de los Medios de Comunicación (AIMC) aporta los siguientes datos en 2010 acerca del establecimiento de nuevas relaciones de los españoles a través de Internet: un 14'5 establece y mantiene relaciones solamente en la red, un 22'3 establece relación tanto dentro como fuera de la red y un $61^{\prime} 4$ no establecieron relaciones sociales en la red.12 El primer dato de mantenimiento de relaciones solamente en la red nos parece discreto, el segundo nos parece más alentador, pues de este modo Internet se convierte en una herramienta útil para conocer gente nueva y establecer lazos reales. El tercer dato nos revela que en España todavía el uso de las redes sociales no está tan desarrollado como en EE. UU.

3.- Efectos psicológicos y sociales de Internet y de las redes sociales.

En este sentido por experiencia personal, hemos observado de aquí unos años un fomento de la socialización gracias a las redes populares como Facebook, Twitter y Tuenti. La creación de las redes ha surgido en un momento en el que el ritmo de vida es tan acelerado que nos impide mantener el contacto como

\footnotetext{
${ }^{12}$ Asociación para la Investigación de los Medios de Comunicación (AIMC), (02-2010) NAVEGANTES EN LA RED, Madrid, p. 117. Recuperado el 12 de diciembre de 2011, de http://www.aimc.es 
quisiéramos con amigos y conocidos, y de este modo, con pocos minutos al día podemos seguir en contacto y presentes.

Según Javier Celaya las motivaciones para participar en las redes sociales son diversas: buscar trabajo, ligar, poner en contacto con antiguos colegas del trabajo o de la universidad, como canal de comunicación, y ocio. Sin embargo, muchas personas buscan cierto reconocimiento social. Estos usuarios complementan su imagen en su vida real con una reputación virtual.13

En Facebook puedes crear tu perfil con datos sobre tu edad, estado civil, gustos, trabajo o estudios, sin coste. Después puedes agregar amigos utilizando la cuenta de correo que mantengas, o buscar amigos que estén en tus amigos, u otros que estén ya en Facebook. Así tener un grupo de unos doscientos amigos es lo normal. Aunque lo que suele predominar no son amigos, sino conocidos. Puedes colgar álbumes de fotos de viajes 0 experiencias, escribir en el estado tu estado emocional o algo que quieras compartir (pensamiento, noticia, etc.), o bien escribir en el muro otro comentario, video, música, etc. de forma que puede quedar a la vista de todos los internautas o sólo de tus amigos. Este método es una manera de encontrar y volver a saber del otro, de seguir en contacto y estrechar el vínculo, aunque el otro esté a cientos de kilómetros. También se puede invitar a fiestas o eventos en los que confirmas o no tu asistencia.

Las desventajas que encontramos en el uso de esta red social es la falta de privacidad, el hecho de estar como en un escaparate dando lugar al cotilleo por parte de los contactos o de los internautas, si no se acota quien tiene acceso a visitar tu perfil.

Twitter es utilizado principalmente por adultos con el fin de dar a conocer alguna actividad, o simplemente un pensamiento. Se puede escribir un mensaje que no supere cierto número de caracteres. También es un medio para estar en contacto con amigos y conocidos. Tuenti es otra red social usada más por jóvenes con posibilidades de compartir información y formar foro y registrar por qué zona sueles salir en momentos de ocio, etc.

\footnotetext{
${ }^{13}$ CELAYA, J., (2008), op.cit., p.150.

REDMARKA UIMA-Universidad de A Coruña - CIECID 
A continuación daremos algunos datos para darnos cuenta del alcance de estas redes hoy en día. Trusov y otros comentan que según el estudio de comScore Media Metrix en 2006 cada segundo algún usuario en los EE.UU. ha visitado al menos quince de las redes sociales más suscritas. Aproximadamente cincuenta redes sociales tiene más de un millón de inscritos, y existen otras docenas de sitios aunque más pequeños, por ejemplo, Wikipedia (2008), Compete.com (2008). Una web de una compañía de análisis de tráfico anunció que la red social más grande era MySpace con cincuenta y seis millones de visitantes por mes, seguido por Facebook, con cuarenta y nueve millones de visitantes.14Unos años más tarde, según comScore, Facebook supera a MySpace pasando de los 52 millones de visitas en junio de 2007 a los 132 millones en junio de 2008, lo que se traduce en una tasa de crecimiento del $153 \% .15$

El estudio de 2010 de la Asociación para la investigación de los Medios de Comunicación (AIMC) española mantiene que un $61,7 \%$ de los usuarios españoles participa en Facebook, seguido de Tuenti 20 '8\%, Windows Live Spaces 13\%, MySpace, 10'1\%, Twitter8'7, Hi5 7’7\%, Linkedin 7’1\%, Badoo 5’4\%, Fotolog 5\%, Xing4'5\%, Sonico 2’9\%, Netlog2’2\%, Orkut 1'3, Metroflog $00^{\prime} 7 \%$, Bebo0' $3 \%$, otras $2 \%$, no las utiliza un $28^{\prime} 4 \%$ de los encuestados 16 . En la pregunta de por qué utilizan las redes sociales, los usuarios contestan que para las relaciones de amistad $79{ }^{\prime} 3 \%$, para hobbies $27 \%$, relaciones profesionales $23{ }^{\prime} 6 \%$, búsqueda de pareja 3 '2, otros $10^{\prime} 8$, no los utiliza un 9\%17. De las webs más visitadas la primera más mencionada es el buscador Google, la segunda el periódico El país y el tercero es una red social, Facebook.18

Respecto a los efectos psicológicos del uso de las redes sociales, hay opiniones diversas. Ferrán Ramón Cortés, consultor de comunicación, opina que la pérdida de contacto personal supone una seria amenaza para la

\footnotetext{
${ }^{14}$ Trusov, M. y otros, (09-2009), "EFFECTS OF WORD-OF MOUTH VERSUS TRADITIONAL MARKETING: FINDINGS FROM AN INTERNET SOCIAL NETWORK", Journal of Marketing, vol. 73, p. 92.

${ }^{15}$ Celaya, J., (2008), op.cit., p.96.

${ }^{16}$ Asociación para la Investigación de los Medios de Comunicación (AIMC), op.cit, p. 73. http://www.aimc.es [acc.31.12.2010]

${ }_{17}^{17}$ Ibíd. p.75.

${ }^{18}$ Ibíd, p.89
} 
capacidad de los jóvenes para relacionarse con los demás19. La psicóloga Martine Delfos alerta de que cultivar amistades en el ciberespacio no fomenta que los jóvenes aprendan de la interacción. Por ejemplo, cuando un amigo dice algo desagradable con un click de ratón lo elimina. De esa manera, no aprenden a lidiar con situaciones difíciles y tampoco ven que ese comentario negativo sea el resultado de una conducta propia. Eso lleva a que las relaciones sean superficiales20. Sin embargo, Albert Benschop, sociólogo holandés, opina que:

"existen consecuencias positivas pues un $25 \%$ de las personas entre 50 y 70 años crea nuevos contactos por Internet, de los que algunos de ellos acaban conociéndose personalmente. Además para poder comunicarse hay que escribir, y esto nos obliga a plasmar en palabras lo que sentimos. Leyendo y escribiendo se recuerda mejor lo que se dice, y eso eleva la amistad a un nivel superior.21"

Manuel Castells, en este sentido positivo, comenta un estudio de observación de la British Telecom titulado "Aquí no pasa nada". Este estudio realizado durante un año en una serie de hogares en los que se utilizaba Internet asegura que la gente siguió haciendo lo que hacía, el que tenía amigos, los tenía en Internet y quien no los tenía tampoco los tenía por Internet.22 El catalán glosa otros estudios en Canadá y EE. UU. que mostraban que los individuos tenían normalmente, como término medio, no más de seis lazos íntimos de relación fuera de la familia, y al mismo tiempo, cientos de lazos débiles. Según Castells Internet se muestra apta para desarrollar lazos débiles, pero no es apta para crear lazos fuertes, como media, y es excelente para continuar y reforzar los lazos fuertes que existen a partir de la relación

\footnotetext{
${ }^{19}$ Cfr. Ramón-Cortes, F., (2008), LA ISLA DE LOS CINCO FAROS, LAS CINCO CLAVES DE LA COMUNICACIÓN, Barcelona: RBA, Barcelona.

${ }^{20}$ Feenstra, C., (12-2010) "RELACIONES EN INTERNET, ¿REALES O VIRTUALES?", Psicologies, ํㅜ 72, p. 70.

${ }^{21}$ Ibíd. p.71

${ }^{22}$ CASTELLS, M., (7-10-2000), op.cit., p. 7-8. 
física.23Castells expone otro estudio muy interesante por la aportación sobre las comunidades virtuales realizado por Barry Wellman quien afirma que las comunidades virtuales en Internet también son comunidades, es decir, generan sociabilidad, generan relaciones y redes de relaciones humanas, pero no son las mismas comunidades que las comunidades físicas. Ambas comunidades se guían por diferentes lógicas y tipos de relaciones. Las comunidades virtuales están basadas en los intereses individuales y en las afinidades y valores entre internautas.24Castells explica otro estudio de Marcia Lipman que aporta otra información valiosa: las comunidades virtuales son más exitosas cuanto más están ligadas a tareas, a hacer cosas o a perseguir intereses comunes juntos.25Castells además se adentra en una reflexión más allá:

Lo que está ocurriendo es que la sociabilidad se está transformando mediante lo que algunos llaman la privatización de la sociabilidad, que es la sociabilidad entre personas que construyen lazos electivos, que no son los que trabajan o viven en un mismo lugar, que coinciden físicamente, sino personas que se buscan.26

Este factor lo estimamos importante, cambia el modo de vivir la sociabilidad, ya no tienes que limarte en las relaciones sociales reales, puedes elegir con quién quieres relacionarte de forma más cómoda y fácil, aunque esté muy lejos de forma virtual, pero no deja de ser una relación seudo-real. La desventaja de este factor es que fomenta el individualismo en las relaciones reales porque el individuo se vuelve más cómodo más indiferente en las relaciones sociales.

Asimismo hemos percibido una vertiente negativa del fenómeno por desgracia: el uso compulsivo o exagerado de Internet, tal y como se desprende del crecimiento de los ciudadanos con adicciones a las Nuevas Tecnologías tanto del uso de Internet, de los videojuegos, de los juegos de rol o el apego al

\footnotetext{
23 Ibíd. p.11.

${ }^{24}$ Ibíd. p. 8.

${ }^{25}$ lbíd. p. 9.

${ }^{26}$ Ibíd. p. 8.
} 
móvil.27 Otros psicólogos, en cambio, si encuentran útil el uso de redes sociales para los pacientes con fobia social como modo de introducirse de forma cómoda en un entorno social.

Es interesante también lo que nos ofrece el estudio del campo de las emociones. Miquel Rodrigo Alsina explica que el estudio en "Sociología de la comunicación" sobre los efectos emotivos es uno de los temas menos explorados y las investigaciones son escasas28. No desarrollamos esta cuestión más en este artículo por cuestión de extensión -aunque si hemos profundizado en ella en una investigación de tesis doctoral29-, sin embargo, esbozamos algunos planteamientos para que se descubra su interés.

En este epígrafe introducimos el tema de la emoción de forma breve desde cuatro aspectos para sugerir el alcance del efecto interaccional mediante este medio: el primero aborda la experiencia emotiva o la diversión emocional en el uso de una red social; el segundo, la emoción como medio cognoscitivo; el tercero, la emoción con relación a los efectos en la conducta. El desarrollo del primer aspecto, la experiencia emotiva, y el segundo, la emoción como medio cognoscitivo, explican por qué les damos importancia: la emoción hace atractiva y posible la transmisión de un valor. Primero, mientras se comunican dos internautas tiene lugar una "experiencia emotiva", que es una forma de diversión emocional; segundo, es un "medio cognoscitivo", pues pueden emitirse juicios valorativos a través de la emoción que nos sugiere lo que el otro nos transmite o comparte, que, además, pueden ejercer una influencia decisiva sobre los juicios emitidos desde la razón. Todo esto proceso forma parte de la asimilación individual del valor al que hemos aludido anteriormente.

El tercer aspecto es la relación de la emoción con efectos conductuales, actitudinales y cognitivos. Antonio Lucas Marín explica que en el estudio de los efectos se pueden observar tres tipologías principales: los conductuales, los actitudinales y los cognitivos, relacionados entre sí en la comunicación

${ }^{27}$ Cfr. Romero, J. M., (12-2010)“¿ES ADICTO A INTERNET?”, Psicología Práctica, 140, pp.5458.

${ }^{28}$ Rodrigo Alsina, M., (1995), LOS MODELOS DE LA COMUNICACIÓN, 2 $2^{\mathrm{a}}$ ed., Madrid: Tecnos, p. 139.

${ }^{29}$ Peña Acuña, B., (2010), HUMANISMO Y CINE: EL TRATAMIENTO DE LA DIGNIDAD HUMANA EN LA OBRA DE STEVEN SPIELBERG, Alicante: Universidad de Alicante, tesis inédita. 
televisiva, pero que, en este escrito, podemos extenderlos de modo analógico al intercambio internauta en una red social. Antonio Lucas Marín desarrolla estos tres factores de la siguiente manera:

Sobre el estudio de los efectos conductuales se ha observado un cambio en las conductas de los sujetos receptores, tanto individual como socialmente. Se ha comprobado más en anuncios publicitarios, en la violencia o en las decisiones de voto.

b) Acerca de los efectos actitudinales se ha afirmado que se produce un cambio o refuerzo, aunque no siempre llevan a la acción. Las actitudes las integran componentes racionales y emocionales, y estos últimos son los que predominan en gran número de ocasiones. Algunas veces ocurre también que los componentes intelectuales y emocionales pueden ser inconsistentes.

c) En cuanto a los efectos cognitivos se concibe un cambio o refuerzo en la forma de pensar o percibir determinadas realidades; puede ser la de aprender nueva información o cambiar la forma de pensar como consecuencia de esta nueva información.30

Consideramos acertada la afirmación de Armon-Jones en "The social construction of emotions" (1988) sobre la transmisión de patrones de conducta en situaciones emotivas desde un punto constructivista. Enuncia este autor:

Los medios de comunicación nos ofrecen modelos de conducta emocional, valores, normas y expectativas. [...], me parece indiscutible que los medios de comunicación establecen patrones de conducta en situaciones emotivas.31

\footnotetext{
${ }^{30}$ Lucas Marín, A., y otros, (1999), SOCIOLOGíA DE LA COMUNICACIÓN, Madrid: Trotta, p. 225.

${ }^{31}$ Rodrigo Alsina, M.,(1995) op.cit, p.139

REDMARKA UIMA-Universidad de A Coruña - CIECID

Año IV, Número 7, (2011), v2 pp. 3-24

http://www.redmarka.org/ 
Otro factor diverso, pero destacable consiste en sopesar que la libre circulación que permite el ciberespacio y las redes sociales pueda propiciar la socialización, es decir, que introduzca el cambio, la dinamización social o incorpore elementos a la sociedad.

Aventuramos, en este sentido, que la capacidad socializadora del uso de los medios que facilita Internet (como son los chats o los foros) y, en concreto, las redes sociales cuando se comparte una noticia o una opinión política o moral, implican una acción universalizadora y multiplicadora de los contenidos, que puede crear estereotipos, e incluso una homogeneización de un público de por sí heterogéneo que por otro medio sería un proceso más complicado, que sin embargo, está unido por una misma vivencia y reacción ante un evento social o cultural.

\section{Conclusiones}

PRIMERA. La red es un fenómeno complejo con varias facetas, pues es un medio de comunicación, una plataforma de interacción y de organización social que reproduce, y por tanto, se adapta perfectamente, a la propia naturaleza social del hombre y a su modo de relacionarse. De esa manera, podemos aventurar que avanzaremos hacia un modo de entender la colectividad- como acuña Manuel Castells-"sociedad red".

SEGUNDA. De los estudios se desprende que actualmente predominan las redes generalistas frente a las profesionales o especializadas. De ellas la que predomina es Facebook. En España en 2010los usuarios utilizan las redes sociales de forma predominante para las relaciones de amistad $79^{\prime} 3 \%$. Otro factor que estimamos importante es la presencia de los internautas en las redes por reconocimiento social.

TERCERA. Si aceptamos la premisa aristotélica de que la naturaleza de la persona se componga por un carácter individual y un aspecto social, -con necesidad de salir de sí y abrirse al otro: amar-, y la teoría interpretativa del interaccionismo simbólico por la que se concibe al emisor y al receptor como 
individuos activos y libres que por la interacción social con los otros participantes conforman los significados que interpretan la realidad social, entendemos que las redes sociales, por el dinamismo relacional que facilitan, juegan y jugarán un papel mayor con el tiempo en la construcción de significados sociales y culturales puesto que han sido acogidos por los planes educativos y por el contexto cultural en los países desarrollados.

Además las redes sociales son plataformas a través de las cuales se pueda dar de forma idónea el aprendizaje social, tal y como establece Erving Goffman, sobre una sociedad que evoluciona rápido planteando nuevas encrucijadas conductuales y éticas. Ciertamente el internauta está expuesto a una dinámica de elección y toma de posición frente a los valores, modelos, estereotipos, estilos de vida, etc., por la misma interacción en su contexto social habitual, que le reclama un posicionamiento al respecto. A la par, se requiere un aprendizaje constante de las expectativas de los otros participantes respecto al papel y al rol que esperan que el internauta represente.

En efecto, nos hallamos en una sociedad donde la curiosidad por otras culturas puede resultar satisfecha a nivel virtual o real, en la que sus habitantes viajan más y el acercamiento global es posible. Si cabe, es en una sociedad que ha adquirido una mentalidad más democrática en la cual se convive en un tejido variopinto de posturas, pues se respetan unas normas comunes, pero es posible la adopción de corrientes culturales exóticas, convenciones novedosas, nuevos planteamientos espirituales, conocimiento de otros sistemas de lance político así como de posturas políticas, o se cuestiona las normas o referentes tradicionales por parte de los individuos o grupos de ellos.

Llegado a este punto del razonamiento, es importante destacar que el actor se ve influido de forma individual por el valor que se transmite a través de las redes, y como hemos dicho, estas plataformas -ya que reproducen el contexto social real-, se muestran idóneas para este proceso de transmisión y asimilación social.

CUARTA. Debido a varios factores de la naturaleza humana para una comunicación eficaz- como la necesidad de la lectura del lenguaje corporal, la necesidad de percepción o contacto físico con el otro, la experiencia emocional 
compartida o el establecimiento de la empatía-, la interacción interpersonal con contacto físico y real es más fuerte que en el medio virtual para el establecimiento de vínculos afectivo-emocionales. Las redes se muestran como un recurso para el ciudadano con el fin de mantener o fomentar la sociabilidad.

QUINTA. La relación virtual si se mantiene per se, no deja de ser ontológicamente una relación seudo-real donde al internauta no se le asegura estar vacunado contra la soledad emocional, pues esta relación que establece es una relación superficial.

SEXTA. Cuando un individuo interactúa en las redes y no fomenta las reales, es un síntoma de que algo no va bien, puede ser una actitud temporal debido a una circunstancia traumática, o una cuestión más seria, con necesidad de terapia psicológica o psiquiátrica.

SÉPTIMA. Según el estudio de AIMC el uso de las redes sociales en España todavía tiene una cota discreta con un $36^{\prime} 8 \%$ de consumidores que hace querencia de ellas frente al uso que se hace en EE.UU.

OCTAVA. Respecto a los efectos psicológicos saludables del uso de las redes sociales, hay opiniones diversas. Los argumentos en contra del uso de plataformas virtuales es la pérdida de contacto personal supone una seria amenaza para la capacidad de los jóvenes para relacionarse con los demás, pues no fomenta que los jóvenes aprendan de la interacción y lleva a que las relaciones sean superficiales. Algunos psicólogos alertan sobre el uso abusivo, compulsivo o adictivo de Internet. Los argumentos a favor de que usen las redes sociales establecen que gracias a Internet se establecen contactos que luego permiten el conocimiento real, que el hecho de escribir y leer desarrolla la memoria y eleva el nivel de amistad. Otra formulación establece que Internet no cambia la capacidad social del individuo. En cambio, en la práctica de la psicología clínica si que se recomienda en la actualidad. 


\section{Bibliografía citada}

Aristóteles (2004) Ética a Nicómaco, Madrid: Losada.

Asociación para la Investigación de los Medios de Comunicación (AIMC), (022010), NAVEGANTES EN LA RED, Madrid. Recuperado el 12 de diciembre de 2011, de http://www.aimc.es

Castells, M., (7-10-2000) "INTERNET Y LA SOCIEDAD RED", Conferencia de presentación del Programa de Doctorado sobre la Sociedad de la información y el Conocimiento, Universitat Oberta de Catalunya,. Recuperado el 11 de diciembre de 2011, de http://tecnologiaedu.us.es/bibliovir/pdf/106.pdf .

Celaya, J. y Herrera, P., (2007) Comunicación empresarial 2.0. La función de las nuevas tecnologías sociales en la estrategia de comunicación empresarial, Barcelona: Grupo MBO.

Celaya, J., (2008), La empresa en la web 2.0, Madrid: Gestión 2000, $3^{\text {a }}$ edición.

Feenstra, C., (12-2010), “Relaciones en Internet, ¿reales o virtuales?", Psicologies, ํㅡ 72.

Goffman, E., (1997), La presentación de la persona en la vida cotidiana, Buenos Aires: Amorrutu editores.

Lucas Marín, A., y otros, (1999), Sociología de la comunicación, Madrid: Trotta. Martín Algarra, M., (2003), Teoría de la comunicación: una propuesta, Madrid: Tecnos.

ORTONY, A. y otros, (1996), La estructura cognitiva de las emociones, Madrid: Siglo XXI.

Peña Acuña, B. y Caldevilla Domínguez, D., (09- 2011), "Nuevas tecnologías, nuevos ciudadanos", Congreso X, Asociación Española de Política y Administración, Murcia. Recuperado el 22 de septiembre de 2011 de http://www.aecpa.es/uploads/files/modules/congress/10/papers/570.pdf

Peña Acuña, B. (2010), Humanismo y cine: el tratamiento de la dignidad humana en la obra de Steven Spielberg, Alicante: Universidad de Alicante, tesis inédita.

Peña Acuña, B, (03-2010), Entender el origen y la naturaleza de Internet, Revista Vivat Academia. Recuperado el 11 de diciembre de 2011, de REDMARKA UIMA-Universidad de A Coruña - CIECID 
http://www.ucm.es/info/vivataca/numeros/n110/ensayos.htm\#entender

Romero, J. M., (12-2010),“¿Es adicto a Internet?”, Psicología Práctica, 140.

Ramón-Cortes, F., (2008), La isla de los cinco faros, las cinco claves de la comunicación, Barcelona: RBA.

Rodrigo Alsina, M., (1995), Los modelos de la comunicación, 2ª ed., Madrid: Tecnos.

Rodrigo Alsina, M., (2001), Teorías de la comunicación: ámbitos, métodos y perspectivas, Barcelona: Bellaterra, Servei de Publicacions de la Universitat Autónoma de Barcelona.

Romero, J. M., (12-2010), “¿Es adicto a Internet?”, Psicología Práctica, no 140, pp. 54-58.

Tanzella Nitti, G., (20-09-1997), "La dimensión teológica de la comunicación”, Roma: Centro Internazionale di Studi, conferencia inédita.

Trusov, M. y otros, (09-2009), "Effects of word-of mouth versus traditional marketing: findings from an internet social network", Journal of Marketing, vol. 73, pp. 90-102.

VV. AA., Diccionario de la real academia de la lengua española. Recuperado el 12 de diciembre de 2011, de http://buscon.rae.es/drael/SrvltConsulta?TIPO BUS=3\&LEMA=empatía

Para citar este artículo:

Peña Acuña, Beatriz (15-12-2011). LA SOCIALIZACIÓN A TRAVÉS DE LAS REDES.

REDMARKA - CIECID - Unidad de Investigación en Marketing Aplicado-Universidad de A Coruña

Año IV, Número 7, V2, pp.3-24

ISSN $1852-2300$

URL del Documento : cienciared.com.ar/ra/doc.php?n=1599

URL de la Revista : cienciared.com.ar/ra/revista.php?wid=39 